\title{
GCU
}

Glasgow Caledonian

University

University for the Common Good

\section{Higher education learner identity for successful student transitions}

\author{
MacFarlane, Karen
}

Published in:

Higher Education Research and Development

DOI:

10.1080/07294360.2018.1477742

Publication date:

2018

Document Version

Author accepted manuscript

Link to publication in ResearchOnline

Citation for published version (Harvard):

MacFarlane, K 2018, 'Higher education learner identity for successful student transitions', Higher Education

Research and Development, vol. 37, no. 6, pp. 1201-1215. https://doi.org/10.1080/07294360.2018.1477742

\section{General rights}

Copyright and moral rights for the publications made accessible in the public portal are retained by the authors and/or other copyright owners and it is a condition of accessing publications that users recognise and abide by the legal requirements associated with these rights.

Take down policy

If you believe that this document breaches copyright please view our takedown policy at https://edshare.gcu.ac.uk/id/eprint/5179 for details of how to contact us. 


\title{
Higher Education Learner Identity for Successful Student Transitions
}

\begin{abstract}
Student success in higher education is dependent on the possession of a positive learner identity, the development of which is a complex longitudinal process of change. Exploring the growth of learner identity within the transition between school and university is therefore apposite, especially for learners from disadvantaged backgrounds who may not have sufficient cultural capital to make an easy intellectual transition from school pupil to university student. Learner identity is positively linked with both the academic and social context of learning as well as with concepts of engagement and a sense of belonging in higher education. This paper explores the findings of a Scottish study involving 30 students who took part in a unique widening participation model based on immersing learners in the university environment whilst still at school. Findings include evidence of the development of a transformative higher education learner identity which is enabled by an immersive experience of university prior to entry. A model for higher education learning identity formation is suggested. In the context of the current dialogue on fair access and widening participation to higher education internationally, findings point policy makers to the benefits of long-term immersion in HE prior to entry for successful transition to university.
\end{abstract}

Key words: Widening participation; Learner identity; Engagement; Belonging; Transition. 


\section{Higher Education Learner Identity for Successful Student Transitions}

\section{Introduction}

There has been concern about 'widening participation' and breaking down the exclusivity of university education in the UK and globally for the past 30 years. Higher education (HE) in the U.K. has undergone major expansion over this period. What was once the preserve of an elite is now a mass system as concerns with social justice have driven the widening participation agenda. Despite the fact that higher levels of participation have been achieved over this period, figures show that 18 -year olds from Scotland's $20 \%$ least deprived communities are more than four times as likely to enter university as those from the $20 \%$ most deprived communities (Commission on Widening Access, 2016). In Scotland, transition to Higher Education (HE) has therefore taken on a new prominence and is linked largely to the movement into university of the most disadvantaged students: represented in the Scottish Index of Multiple Deprivation (SIMD). Central to the discourse on transitions is the concept of learner identity, the development of which is a complex longitudinal process of change (Briggs, Clark and Hall, 2012). Briggs et al propose that the development of higher education learner identity is essential to student achievement and is initially encouraged where schools, colleges and universities adopt integrated systems of transition. In the context of learners from disadvantaged backgrounds who have unequal access to HE, and especially those who are first generation students, bridging this gap takes on a heightened significance. This paper examines the findings from a study which explored the transitional experiences of school pupils who undertook a unique transition programme involving the study of Scottish Advanced Highers which are HE level qualifications normally delivered in school, in a university. What differentiates this programme is that the aim is to immerse learners in the 
HE environment prior to entry so that pupils become familiar with the HE learning environment, which in turn will support their subsequent progression and retention.

\section{Learner identity formation}

An extensive overview of existing identity development theories is beyond the scope of this paper. Learner identity is commonly understood to be a temporary identity which is socially constructed. That is, one's sense of self and beliefs about one's own social group as well as others are constructed through interactions with the broader social context in which dominant values dictate norms and expectations (McEwen, 2003). An example of these broader social contexts is education and a number of researchers have paid considerable attention to the interplay between student identity and institutional culture in HE. Drawing on Bourdieu's notion of 'dispositions' Field and Morgan-Klein (2010: 4) define studenthood as, 'the ways in which the learner thinks of themselves as being a student, including the extent to which they develop an identity as a student'. They emphasise the importance of developing a sense of oneself as a 'student' and moot that we would expect retention rates to be higher among those learners who have a well-developed sense of themselves as fitting the role of student. The context of these studies is not dissimilar to the local context of this research.

There exists a substantial body of work outlining the complexity of learner identity formation as this relates to learners who have no previous experience of HE. In this context, feelings of alienation, isolation and 'not fitting in' are apparent (Bowl, 2001; Thomas 2012). Students from non-traditional backgrounds experience transition differently from second generation 
students who are already in possession of certain attributes or 'cultural capital' prior to university entry (Leese, 2010). Inequalities of social class and the concept of learner identity are thus inextricably linked and affect the ways in which people construct, experience and negotiate different educational opportunities and routes (Archer \& Leathwood, 2003). This does not mean however, that identity as it applies to learners from disadvantaged backgrounds should be conceptualized in deficit terms. On the contrary, Archer and Leathwood (2003: 175) contend that there is no singular 'working class identity'. Rather, that there is a multitude of ways through which working-class learners actively resist, or embrace, HE as a possibility. Eccleston (2009) has suggested that the process of engaging in an educational programme with its intrinsic 'learning community' may change an individual's 'horizons of actions' leading to new career trajectories. Moreover, James et al (2015) argue that when immersed in new fields, HE students can develop strategies and nuanced understandings of their previous experiences, social background and different learning cultures and contexts to inform the development of their learner identities.

The developmental perspective of learner identity presented by Hussey and Smith (2010) presents transition as a continuous process, ongoing throughout the student lifecycle and accommodating changing and shifting identity. Huon and Sankey (2002) have drawn attention to the point of entry to $\mathrm{HE}$ as being of particular significance for the transformation required in learner identity.

Learner identity is also closely aligned with a sense of belonging and engagement (Bliuc et al 2011). Thomas (2012) argues that that curriculum is of central importance to developing confidence and fostering a sense of belonging and engagement in HE. Osterman (2000) argues that learners' sense of belonging is directly related to their engagement with the 
academic process and Kuh (2009) relates it to the time and effort invested by the student, levels of participation and contacts made as an undergraduate. In addition, engagement and belonging in HE impact on retention. For example, Trowler (2010) believes that students will not transition successfully through university if they feel that they do not belong or if they are not fully engaged with their learning.

What is clear from the literature is that transitions to and within HE involve radical shifts in learner identity and that learners from disadvantaged backgrounds can experience significant disequilibrium in their notion of self when faced with such periods of change. In terms of the social inclusion agenda, therefore, fostering a higher education leaning identity is essential for positive transitions.

A central question addressed in the current study was in what way the immersion in HE for the study of Advanced Highers contributes to the development of a higher education learner identity for learners whilst still at school. If pupils attending the Centre are to truly benefit from the opportunity to study within a university environment then one would hope that this experience would be reflected in their ideas of themselves as university students or at least as potential students. This would in turn equip participating pupils with the learner identity for positive transitions to HE destinations. The model of the Advanced Higher Centre described in this paper can be seen as the site where there is potential for learner identity to undergo a structuring or restructuring from one of school 'pupil' to university 'student.' Thus, the literature review developed two key research question relating to learner identity and successful student transitions: 
Research Question 1.

To what extent does immersion in higher education whilst still at school facilitate the development of a higher education leaner identity for learners from disadvantaged backgrounds?

Research Question 2.

In what way does developing a higher education learner identity prior to university entry contribute to successful student transition for learners from disadvantaged backgrounds?

\section{Higher and Advanced Higher Participation}

In Scotland the post-compulsory school systems comprises Secondary 5 and Secondary 6. Pupils can go to university at the end of S5 as Highers provide the entry requirements for Scottish universities where degrees are normally four years long. However, recently it is more common for students to remain until S6 taking further Highers or progressing to Advanced Highers at around 17-18 years of age. The majority of English universities, the most popular choice for students wishing to study outside of Scotland, require Advanced Higher qualification levels as these are deemed by the English universities to be most similar to A levels. In addition, while Highers remain the 'gold standard' for university entry in Scotland, increasingly Advanced Highers, where studied, are becoming a condition of entry and, in some cases, can lead to direct entry to year two of a degree. Thus providing fair access to Advanced Higher qualifications is central objective of the Scottish Government's policy, recently outlined in, 'A Blueprint for Fairness' which makes a number of recommendations to support the achievement of the key target that by $2030,20 \%$ of entrants 
to higher education must come from the $20 \%$ most deprived areas in Scotland (Commission on Widening Access, 2016).

Many schools, particularly in Glasgow, struggle to provide a range of Advanced Higher courses to their final year pupils for a variety of reasons including small pupil numbers, timetabling constraints and lack of teacher expertise or resources. Pupils often then repeat Highers or take classes that are not directly related to their choice of post-school destination, in order to fill their timetable. Thus, pupils in their final post-compulsory school year (S6) from secondary schools in Glasgow which fall within the two lowest quintiles (MD20/MD40) of the SIMD are targeted for inclusion in the Advanced Higher Centre. The current average HE progression rate for pupils in these schools is $19 \%$, whereas the Scottish sector average for state funded secondary schools is $37 \%$ and for Glasgow is 29\% (Scottish Funding Council, 2013). The Centre, established in 2013, provides an immersive year-long programme where school pupils study Advanced Highers within the university environment for up to 18 hours per week. They are registered students and have access to the full range of resources and facilities.

\section{Methodology}

A qualitative methodological approach was adopted. Data about the destinations of all former Advanced Higher Hub pupils is not known as a robust tracking system is not in place due to the inherent difficulties of following pupils from one institution to another (from school to college or university). Therefore, participants were self-selecting from a list provided by the Centre's staff of former pupils about whom destinations were known. To this extent the 
sample could be described as a 'convenience sample'. This has implications in terms of the generalisability of the findings since, for example, pupils who did not progress to university post the intervention and pupils who progressed to college are not included in the sample.

Ethical approval for the study was sought and granted. The Centre Manager acted as a gatekeeper in terms of contact with former Centre pupils. In-depth one-to-one semi-structured interviews were undertaken with a total of 30 university students who had undertaken Advanced Highers as part of the programme. Questions, which were open-ended, covered a range of areas in relation to the students' experiences of studying at the Centre and their subsequent experiences of the transition to and through university. Interviews were transcribed and a 6 phase thematic analysis of the data was undertaken to identify key themes across the dataset which related to the research questions (Braun \& Clarke, 2006). This involved: familiarisation with the data set; generating initial codes to identify a feature of the data and collating the data by code; searching for themes; reviewing and refining themes; defining and naming themes, counting the number of respondents who mentioned and provided evidence for each theme and writing up the analysis by theme with reference to the research questions. Specifically, an inductive or 'bottom up' analytic approach to thematic analysis was used whereby analysis was guided by the themes that emerged from the data, rather than by prior theoretical accounts. The host institution is a post-92 institution with a strong tradition as a 'widening participation' university. Its undergraduate profile includes $20 \%$ of students from the $20 \%$ most deprived areas of the population and $40 \%$ of students from the $40 \%$ most deprived areas.

Nineteen female and 11 male students were interviewed. In terms of level of study, most interviewees were first year students (16) while 9 were second year students and 5 were third 
year students. Participants were engaged in a range of different degree programmes at a total of 8 universities U.K. wide although most were based in Scotland and the majority were attending Glasgow based institutions.

Twenty-six of the 30 participants $(87 \%)$ came from the two lowest quintiles of the SIMD (MD40) while 67\% came from the lowest quintile (MD20). Twenty-one participants (70\% of the sample) were the first generation to attend university.

\section{Findings and discussion}

The analysis draws on the perspective that learner identity is a socially constructed concept (Lawler, 2014). Participants are identified only by number (P1-P30). A thematic analysis of the interview data revealed 6 broad and overlapping factors which facilitated the development of an HE leaner identity. These include: academic skills developed in the study of HE level qualifications, independent learning, social relations, personal and social skills, engaged learning and the development of a sense of belonging in Higher Education.

\section{Academic skills}

The range of academic skills developed in the study of Advanced Highers at the Centre included research skills such as information gathering, note-taking and research methods. Critical analysis skills were also acquired including critical thinking, presenting an argument and problem solving. Academic writing skills reported involved essay and report writing, 
laboratory reports, completing a dissertation and referencing. Other skills cited included handling scientific equipment, presentation skills, exam skills, communication skills and online learning. One could argue that the above skill sets are those which are engendered through the study of Advanced Higher(s) regardless of the location of delivery. However, those participants who studied Advanced Highers at both university and at school simultaneously (in the case where these were available) described how certain skills were not acquired in school as the course organisation and teaching were different:

'In school there were only two of us doing Advanced Higher English. We had three different teachers. It was all off timetable; we were fitted in to their free periods. They had other commitments and were sometimes called away and our class was cancelled.' (P22)

Developing the academic skills associated with HE was thus considered important to participants in terms of preparation for their degree studies. However, simply obtaining the academic skills was insufficient to aid the progression to university in a significant way. What was considered more important was the development of independent learning and personal and social skills which were fostered through the immersive experience in university. In response to a question about how the university learning experience was different to that which participants were used to, 21 interviewees ( $70 \%$ of the sample) mentioned developing as independent learners.

\section{Independent learning}


Those participants who listed independent learning as a feature which contributed to their overall experience at the Centre wished to stress this as a key factor which aided their feelings of studenthood and which helped their transition to university:

'It's the independent learning that makes you feel like a student. You had to go away and source materials, do your own reading and come up with a presentation for the group which was followed by a discussion. In that way it's much the same as a tutorial.' (P2)

Briggs et al (2012) argue that helping learners to develop independent learning skills pre- and post-entry is an important factor that enables the growth of student identity. Fazey and Fazey (2001) argue that students arrive at university with the potential to be autonomous in their learning and that it is the responsibility of those who structure the learning environment to nurture undergraduate potential if autonomous behaviour is to be realised as an outcome of HE. The opportunity for independent learning which was fostered at the Centre both aided participants' preparation for this kind of learning at university and contributed to a sense of becoming a student.

\section{Social Relations}

Participants reported that the transition from school pupil to university student was facilitated by meeting new friends $(\mathrm{N}=28,93 \%)$ and by their less formal relationships with teachers within the university setting $(\mathrm{N}=22,73 \%)$. Participants enjoyed being treated like adults, like 
students and being treated with respect. They felt that they were given more responsibility to work independently and were trusted to study and to complete assignments at home. All those who mentioned the teacher-learner relationship reported being on first name terms with teachers which made them feel mature. Personal relationships are essential to forming HE learner identity pre-transition (Briggs et al, 2012). This is because positive contacts with other learners and staff help to sustain and build identity during and after transition. A less formal relationship with teaching staff at the Centre than pupils were used to at school impacted on their maturity which they recognised would be required at university:

'I felt like a student very early on. We called the teaching staff by their first names. We were treated with respect, as young adults.' (P9)

The less formal relations with staff than participants were used to at school thus facilitated both maturity and a learner identity as 'student'. This finding resonates with Mathews (2016) who argues that positioning both students and academic staff as 'essential players' in the learning experience should become the cultural norm within universities. Relationships with peers, especially with new friends made at the Centre were important in terms of impact on the formation of a higher education learner identity. This was especially the case for those participants who attended the Centre from a school on their own. The vast majority of participants in the study mentioned the benefits of meeting new people at the Centre and for many this experience served to build the confidence and maturity to develop new friendships and networks at university. Being around other learners from different schools who were of a like mind in terms of their positive attitude to learning was also seen as contributing to a new sense of self: 
'When I started at the Centre it felt like I was leaving school already. It was a different world full of smart, like-minded people who liked maths and were into their sciences like me.' (P14)

The opportunity to form positive social relationships with other students and academic staff is cited as promoting an HE learner identity by Keup and Barefoot (2005).

\section{Sense of Belonging}

The university campus environment clearly had an impact in facilitating a learner identity as 'student' in terms of facilitating a sense of belonging in HE. Eighteen participants $(60 \%)$ reported having developed a sense of belonging with the university environment. Pupils were given associate student status and were issued with student cards. Having a student card, a university email address and login details for computers on campus were reported to facilitate both a sense of belonging to the institution as well as contributing to a student identity. The physical environment was also significant especially the library which was used by participants both to study for their exams and as a social place to meet and get to know each other as well as to mingle with undergraduate students:

'It was just everything - the buildings, not being in uniform, the cafes, the library which is a special place; the clubs and societies which you can join and having a student card immediately makes you feel like a student.' (P25) 
This finding echoes Mathews (2011) who has drawn attention to the fact that social learning spaces can contribute to enhanced student engagement by fostering active learning, social interaction and belonging in higher education.

A recurring theme in interviews with students was the importance of not having to wear school uniform which aided their sense of studenthood $(\mathrm{N}=18,60 \%)$. Sometimes, however, it was not always possible for pupils to avoid wearing uniform, for example, on days when they either came to university straight from school or vice versa. This was seen as a barrier to belonging with a total of 5 participants (17\%) of respondents making specific reference to having to wear uniform as 'distancing' them from the student body.

The university facilities and resources were frequently mentioned as adding to the overall student experience and a sense of belonging, in particular the library and the science laboratories which were viewed positively and often compared to those at school. Participants who had studied science subjects at the Centre $(\mathrm{N}=12)$ were also very keen to report the impact working in university laboratories had made:

'When we were in the labs, I didn’t just feel like a student I felt like a scientist.' (P4)

Thus, there is some evidence that the facilities on campus and the laboratory learning environment facilitated not just learner identity as student but also some affiliation with a community of practice (Wenger, 2000). In addition, factors which fostered a sense of belonging in $\mathrm{HE}$ included the university campus environment, access to university facilities 
and resources, having associate student status, being treated like adults, less formal relationships with staff, social relations with new friends and not having to wear school

uniform. Drew, \& Smith, (2006) state that fostering a sense of belonging, 'aids in social and emotional adjustment' to higher education while Morieson et al (2013) support an approach that emphasises a sense of belonging to a programme, a school or faculty, and to university in general.

\section{Engaged learning}

Participants who studied Advanced Highers at the Centre and at school simultaneously $(\mathrm{N}=12)$ drew a comparison about teaching styles. In terms of teaching, many participants commented on the more independent learning and preparation required for subjects delivered at the Centre which they regarded as 'quite different' and 'beneficial'. The 'flipped classroom' approach meant that pupils were expected to complete work ahead of the teaching of a topic. This approach was said to foster independent learning, motivation and selfdiscipline:

'This is much more like university. It fosters self-discipline and independent learning and motivation. It has served me well here.' (P4)

This finding concurs with that of Keup and Barefoot (2005) who found that first year seminars were an effective means of facilitating the transition from school to college. 
Seminars and tutorials allow students a feeling of personal success at establishing a network of peers, forging meaningful connections with peers and staff.

Participants reflected on the content of their Advanced Higher courses and the way in which the classes were taught which helped to engage their learning:

'Coming to the Centre re-engaged me with other wider societal issues like politics. At school it's a different learning environment and a totally different culture.' (P7)

This finding echoes Rubin (2007) who maintains that teaching should engage students and encourage them to develop broader understandings of issues of concern. In this way the discourse of the classroom validates students as learners, encouraging participation and reiterating the belief that students' ideas are worthwhile and their learning is important and purposeful.

For those pupils who had undertaken Advanced Highers in science subjects $(\mathrm{N}=12)$, learning within in a university laboratory environment was an especially engaging experience and compared favourably to their past experiences of science at school:

'We had fantastic resources: pipettes that aren't broken and Bunsen burners which actually work. I cultured bacteria in Biology using amazing equipment. Now when I'm in a lab I know how to use the equipment.' (P24) 
Another area where there were differences compared with participants' school experience of learning was the increased use of online technology both for retrieving general information such as timetables and assignments and for online learning. Again, this was viewed as good preparation for university where a significant amount of course material is posted online:

'Using the online learning environment, which is different to the one used at the university I now attend, but was still extremely helpful.' (P22)

Coates (2007) moots that learning how to engage in effective ways with university study should be part of every university student's educational experience. As part of this he argues that increasingly powerful and pervasive online technologies should be leveraged to enhance campus-based student engagement. In addition to an increased use of online learning, factors contributing to engaged learning within the immersive HE experience of the Centre included more independent learning, the 'flipped classroom' approach, teaching which was more like tutorials than school classes, the content of the course, the university laboratories and resources, being afforded the opportunity to attend some lectures and using the library to study. These findings support Kahu's socio-cultural model of transition and engagement.

\section{Personal and social skills}

All 30 participants (100\% of the sample) described having developed personal and social skills at the Centre. These included confidence, independence, motivation, work ethic, self- 
efficacy and maturity. Developing social skills through meeting new people was considered vital in terms of preparation for the transition to university and was highlighted by every participant. Increased confidence was the most reported outcome of studying within a university environment. All $30(100 \%)$ participants said that their confidence had increased as a result of completing the programme. Increased confidence was attributed to the social side of university and in particular to meeting new people. This was particularly the case for those participants who had attended university from a school on their own:

'In tutorials, if I hadn't had the experience of having to speak up in front of lots of new people I would have found it much more difficult to be prepared to contribute in these.' (P21)

For many participants this confidence aided self-efficacy and engendered a sense of belonging in the HE environment:

'The confidence I gained has helped me to feel that I'm good enough to attend university and that I belong there.' (P14)

Twenty-five participants ( $83 \%)$ said that they also felt more independent at the end of the programme:

'I can't emphasise enough the sense of independence it gives you. It's like a trial run of uni. In school you are spoon fed all the time.' (P13) 
Five participants reported increased feelings of self-worth and acceptance from early on in their experience at the Centre. Being around other like-minded people was said to contribute to this especially being around others for whom learning was important:

'Students are smart, right? You won't feel like a student if you don't feel smart and you're not going to feel smart unless it's ok to be smart. The Centre gives you that environment.' (P14)

This finding resonates with Christie et al (2007) who note that transition to university is an emotional process. How students learn depends not just upon the individual's emotional commitment to developing a new learning identity but on the emotional interaction between the student and the learning environment of the university.

Increased motivation was reported by many participants $(\mathrm{N}=13,43 \%)$. For some this came about as a result of the focus on independent learning but was enhanced by the participatory nature of the learning environment:

'The self-motivation required to work independently was the major thing for me. My subject has little contact time so you need to prepare and do a lot of independent work.' (P24)

Tranter (2003) argues that students from disadvantaged backgrounds appear to need an extraordinary degree of self-motivation, a level of motivation which, she argues is far above 
that held by most of their middle class fellow students at university. Zimmerman et al (1992) also contend that self-efficacy is a predictor of motivational outcomes and academic achievement.

Social skills were deemed of relevance for meeting new people at university and in particular, for those moving away from home to attend university. Friendships developed at the Centre at times carried on into university regardless of whether the students were at the same university. The experience of developing new skills made participants feel more prepared for university. New friendships, relationships and networks encouraged a sense of belonging in HE and without these the transition would have been a bigger 'step', 'leap' or 'jump.' Indeed four participants used the word 'bridge' to describe what the Centre provided in terms of transition to university.

'The jump to university would have been much bigger. Meeting new people became easier and I was used to the travelling in and out to university.' (P1)

\section{Higher Education learner identity formation}

Participants were asked when they made the intellectual transition from school pupil to university student and what contributed to this distinction? Twenty six participants $(87 \%)$ reported that the transition from school 'pupil' to university 'student' started at the Centre; that is before they made the transition to university. Only 4 participants reported first feeling like a student when they started university in earnest. Of those, one said that, 'just being at 
university properly' had led to this distinction. Another participant reported that she had felt she was really just 'playing' at being a student until she left home. For two participants having to wear school uniform whilst attending the Centre prevented the intellectual transition from pupil to student. Even those participants who reported not feeling like 'proper' students until they had entered first year at university regarded their experience at the Centre as a positive step towards this transformation:

'I was like 50/50; a pupil at school but more of a student when I was on campus.

Because I wasn't completely detached from school this didn't progress to $100 \%$ until I came to university.' (P23)

In summary, the immersive experience of studying HE level qualifications within a university environment whilst still at school fosters the development of a positive HE learner identity. For the vast majority of participants the intellectual transition from school 'pupil' to university 'student' started at the Centre and was nurtured via the opportunity to develop academic skills and become independent learners. Learning and teaching experiences that are participatory and engaging were also significant in evolving this transition and university facilities and resources contributed here. Interpersonal relations with new peers and teaching staff aid the development of personal and social skills which were viewed as being essential for transition. Increased confidence and independence are the two most significant personal outcomes of the immersive experience in HE followed by motivation, work ethic, selfefficacy and maturity. Being afforded associate student status, being treated like adults, not having to wear school uniform and the less formal relations with staff allowed a sense of belonging to university and fostered a sense of self as 'student'. The impact of these 6 key factors (academic skills; independent learning; social relations; personal skills; engaged 
learning and a sense of belonging) is a transformational intellectual transition from school pupil to university student. Without the formation of an HE learner identity the transition to higher education would have been a much bigger 'leap.' What is clear from the findings is that the development of an HE learner identity is a social as opposed to a personal phenomenon; it was the immersive experience in higher education constituted by new social relations with like-minded peers which had most bearing on identity formation as 'student'. The evolution of a higher education learner identity is summarised in figure 1.

Fig. 1. Higher Education learner identity formation

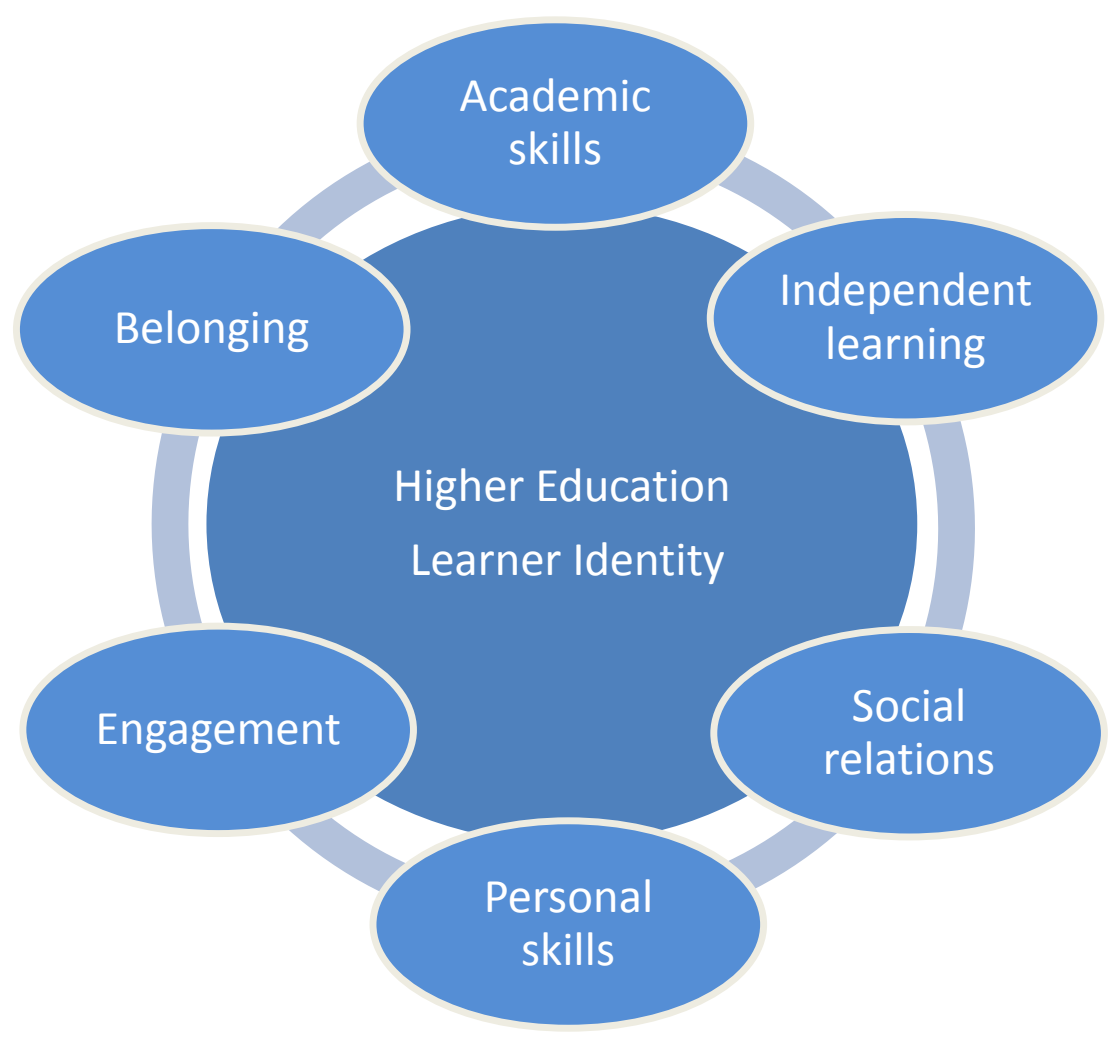




\section{Discussion}

It is worth noting the potential challenges involved in developing programmes such as the one described here. A considerable amount of planning is required in advance of receiving the first cohort of school pupils onto campus. This includes consultation with colleagues across the institution to ensure that access to all practical elements of being a university student is available to pupils. Issues such as arranging suitable accommodation, registering pupils as associate students, attaching pupils to the university online environment and setting up a training programme on how to use the library facilities, all require to be addressed. The resource implications of such a programme are not insignificant as costs for teaching, field trips, materials and reprographics have to be met in addition, of course, to providing travel to and from school to university. Importantly, certain frameworks are required to be put in place relating to the safety and pastoral care of pupils and these should take cognisance of child protection and vulnerable young adult protocols. Systems to monitor pupil attendance and assessment reporting are required. Key to the success of the programme has been the development of working relations and communication links with partner schools, including providing daily updates regarding attendance or any concerns about pupils.

High demand degree programmes such as medicine and dentistry now require Advanced Highers for entry. In the current study a total of 7 pupils attended the Centre in order to obtain Advanced Highers for such programmes. Had these qualifications not been available at the Centre these pupils would not have had the opportunity to apply for these programmes since the Advanced Highers in the subjects they required were not available in school. Moreover, the opportunity to study Advanced Higher level provides pupils with an 
opportunity to test out the level and workload of first year university work since, under the Scottish Credit and Qualifications Framework, Advanced Highers are equivalent in terms of level (SCQF level 7).

\section{Conclusion}

This study found that, for learners from disadvantaged backgrounds, immersion in HE whilst still at school facilitates the development of a positive HE leaner identity. While the research draws on only one case and generalisations from such a sample size should be cautioned, evidence from those who took part in the programme indicates that developing a learner identity as an HE student prior to university entry contributes to successful student transition. Learner identity was nurtured via the opportunity to develop academic skills and become independent learners, social relations and networks with new friends and a less formal relationship with teaching staff than participants were used to at school. Personal and social skills including confidence, independence and motivation were facilitated from the experience of studying HE level qualifications within a university environment and had a positive impact in terms of readiness for the transition. Different teaching styles, including the 'flipped classroom' approach engaged learners who drew comparisons with preparation for university tutorials. A sense of belonging in HE was fostered by having full use of the facilities, being around like-minded people, having student cards and not having to wear uniform. Taken together, these key factors facilitated the development of a positive learner identity as HE student prior to entry: the vast majority (87\%) of participants reported that the transition from school 'pupil' to university 'student' started at the Centre; that is before they made the transition to university. 
Despite attempts to demonstrate the efficacy of widening participation interventions, there is a consensus that the evidence in the Scottish context is limited (Riddell et al, 2013, Hunter Blackburn, 2016). Perhaps it is unsurprising to note the apparent dearth of evidence of success of 'access' programmes when we consider that many are short-lived or one-off. The development of learner identity takes time (Field and Morgan-Klein, 2010). This is particularly the case for learners from disadvantaged backgrounds many of whom are first in family to attend university and more likely to develop what Turner (1987) calls 'relational' identity that can account for subjective feelings of being isolated and non-belonging. Studenthood also involves imagined futures (Field and Morgan-Klein, 2010). Thus learner identities will be expressed through, and also shaped by, different ways of seeing the future self. The year-long, immersive model of transition delivered at the Centre provides the time required for a learner identity as student to develop. The fact that the programme is delivered with a university setting allows participants to imagine their future selves as HE students.

As institutions respond to the local, national and global agenda of widening participation, increasing numbers of first generation students will be entering universities worldwide. In order to ensure their academic and personal success institutions will increasingly be required to develop activities to prepare learners for a dual transition: transition from school to university and, more crucially, from school 'pupil' to university 'student'. Noting the caveats around the issues and challenges involved in developing such programmes, policy makers and practitioners should consider the relevance and merits of this approach in their setting. Such an approach has the potential to encourage the development of a transformational HE learner identity to enhance the transitional experience of learners from disadvantaged backgrounds. This article has identified the elements necessary for the development of a higher education learner identity prior to entry and makes a contribution in this regard. 


\section{References}

1. Archer, L. \& Leathwood, C. 2003. Identities, inequalities and higher education in L. Archer, M. Hutchings and A. Ross, Higher Education and Social Class, Issues of exclusion and inclusion. London: Routledge.

2. Bliuc, AM., Ellis, R.A., Goodyear, P. and Muntele Hendres, D. 2011. The role of social identification as university student in learning: relationships between students' social identity, approaches to learning, and academic achievement, Educational Psychology, 31 (5): 559-579.

3. Bowl, M. 2001. Experiencing the barriers: non-traditional student entering higher education, Research Papers in Education, 16 (2): 141-160.

4. Braun, V. \& Clarke, V. (2006). Using thematic analysis in psychology, Qualitative Research in Psychology, 3 (2) 77-101.

5. Briggs, A.R.J., Clark, J. and Hall, I. 2012. Building bridges: understanding student transition to university, Quality in Higher Education, 18 (1): 3-21.

6. Christie, H., Tett, L., Cree, V.E., Hounsell, J. \&McCune, V. 2007. A real rollercoaster of confidence and emotions: learning to be a university student, online 
papers archived by the Institute of Geography, School of Geosciences, University of Edinburgh.

7. Coates, H. 2007. A model of online and general campus-based student engagement, Assessment \& Evaluation in Higher Education, 32 (2).

8. Eccleston, K., 2009. Lost and Found in Transition: Educational implications of concerns about 'identity', 'agency' and 'structure'. In J. Field, J. Gallacher and R. Ingram (Eds.), Researching Transitions in Lifelong Learning.' Oxon: Routledge.

9. Fazey, D. and Fazey, J. 2001. The potential for autonomy in learning: perceptions of competence, motivation and locus of control in first-year undergraduate students. Studies in Higher Education, 26(3): 345-361.

10. Field, J. and Morgan-Klein, N. Studenthood and identification: higher education as a liminal transitional space, University of Stirling, Scotland, Paper presented at the 40th Annual SCUTREA Conference, 6-8 July 2010, University of Warwick, Coventry.

11. Harvey, L. \& Drew, S. with Smith, M. 2006. The First-Year Experience: A review of literature for the Higher Education Academy, London, The Higher Education Academy. 
12. Hunter Blackburn, L., Kadar-Satat, G., Riddell, S. and Weedon, E. 2016. Access in Scotland, Access to higher education for people from less advantaged backgrounds in Scotland, the Sutton Trust. https://www.suttontrust.com/wpcontent/uploads/2016/05/Access-in-Scotland_May2016.pdf

13. Huon, G., \& Sankey, M. (2002, July 8-10). The transition to university: Understanding differences in success. Paper delivered at 6th Pacific Rim, First Year in Higher Education Conference, Changing Agendas - Te Ao Hurihuri, Christchurch, New Zealand. University of Canterbury.

14. Hussey, T., \& Smith, P. (2010). Transitions in higher education. Innovations in Education and Teaching International, 47(2), 155-164.

15. James, N. Busher, H. \& Suttill, B. 2015. Using habitus and field to explore Access to Higher Education students' learning identities, Studies in the Education of Adults, 47 (1): 4-20.

16. Keup, J.R. and Barefoot, B.O. 2005. Learning how to be a successful student: exploring the impact of first-year seminars on student outcomes. Journal of the FirstYear Experience and Students in Transition, 17(1): 11-47.

17. Kuh, G. D. (2009). The national survey of student engagement: Conceptual and empirical foundations. New Directions for Institutional Research, 2009(141), 5-20.

18. Lawler, S. (2014). Identity: Sociological perspectives (2nd ed.). Malden, MA: Polity.

19. Leese, M. 2010. Bridging the gap: supporting student transitions into higher 
education, Journal of Further and Higher Education, Vol, 34, No 2, 239-251.

20. Matthews, K.E., Andrews, V. \& Adams, P. 2011. Social learning spaces and student engagement, Higher Education Research \& Development, 30, (2).

21. Mathews, K.E. 2016. Students as Partners as the Future of Student Engagement, Student Engagement in Higher Education, 1 (1).

22. McEwen, M. K. 2003. The nature and uses of theory. In S.R. Komives, D.B. Woodard, Jr., \& Associates (Eds.), Student services: A handbook for the profession (pp. 153-178). San Francisco: Jossey Bass.

23. Morieson, L., Carlin, D., Clarke, B., Lukas, K. and Wilson, R. 2013. Belonging in education: Lessons from the Belonging Project, The International Journal of the First Year in Higher Education, 4 (2): 87-96.

24. Osterman, K. F. (2000). Students' need for belonging in the school community. Review of Educational Research, 70(3), 323-367.

25. Riddell, S., Edward, S., Boeren, E. \& Weedon, E. 2013. Widening Access to Higher Education: Does Anyone Know What Works? A Report to Universities Scotland. http://www.universities-scotland.ac.uk/uploads/WideningAccessToHE-CREID.pdf

26. Rubin, B.C. 2007. Learner Identity amid Figured Worlds: Constructing (in) competence at an Urban High School, The Urban Review, 39 (2): 217-249. 
27. Scottish Funding Council, 2013. Learning for All: seventh update report on measures of success.

28. A Blueprint for Fairness, the Final Report of the Commission on Widening Access, Scottish Government, 2016. http://www.gov.scot/Publications/2016/03/1439

29. Thomas, L. 2012. Building Student Engagement and Belonging in Higher Education at a Time of Change: final Report from the What Works? Student Retention and Success, Higher Education Academy. https://www.heacademy.ac.uk/resources/detail/what-works-studentretention/What_Works_Summary_Report

30. Tranter, D. 2003. Fish out of Water: Students from Disadvantaged Schools and the University Experience. Refereed paper presented at Creating Spaces: Interdisciplinary Writings in the Social Sciences Conference, Canberra, 17-18 July.

31. Trowler, V. (2010). Student engagement literature review, Report for the Higher Education Academy, published November 2010.

32. Turner, V. 1987. Betwixt and between: The liminal period in rites of passage ${ }^{\text {ee }}$ in L. C. Mahdi, S. Foster and M. Little (Eds.), Betwixt and Between: patterns of masculine and feminine initiation, Peru IL, Open Court.

33. Wenger, E. 1998. Communities of Practice: Learning, meaning, and identity, New York: Cambridge University Press. 
34. Zimmerman, B.J., Bandura, A. \& Martinez-Pons, M. 1992. Self-motivation for Academic Attainment: The Role of Self-Efficacy Beliefs and Personal Goal Setting, American Educational Research Journal, 29 (3): 663-676. 